\title{
Mineralization of layer-by-layer ultrathin films containing microfluidic-produced hydroxyapatite
}

\section{nanorods}

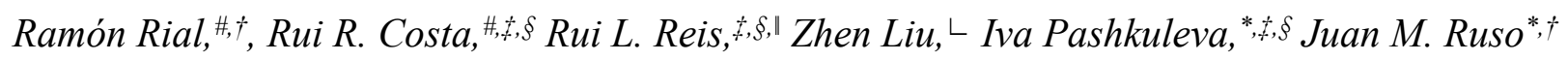

$\dagger$ Soft Matter and Molecular Biophysics Group, Department of Applied Physics, University of Santiago de Compostela, 15782, Santiago de Compostela, Spain

$¥ 3 \mathrm{~B}$ 's Research Group, I3Bs - Research Institute on Biomaterials, Biodegradables and Biomimetics, University of Minho, Headquarters of the European Institute of Excellence on Tissue Engineering and Regenerative Medicine, AvePark, Parque de Ciência e Tecnologia, Zona Industrial da Gandra, 4805-017 Barco, Guimarães, Portugal

§ ICVS/3B's, PT Government Associated Laboratory, Braga/Guimarães, Portugal

I The Discoveries Centre for Regenerative and Precision Medicine, Headquarters at University of Minho, Avepark, 4805-017 Barco, Guimarães, Portugal

$\llcorner$ Department of Physics and Engineering, Frostburg State University, Frostburg, Maryland 21532, United States. 


\begin{abstract}
KEYWORDS. Layer-by-layer, microfluidics, hydroxyapatite, electrostatic interactions, osteoconductivity.
\end{abstract}

\begin{abstract}
We describe the assembly of layer-by-layer (LbL) ultrathin films containing bioactive hydroxyapatite (HAp) rod-shaped nanoparticles with mineralizing capacity. Monodisperse $96 \mathrm{~nm}$ long and $9 \mathrm{~nm}$ wide HAp nanorods with a surface charge of $-14 \mathrm{mV}$ were produced with a microfluidic system. The negatively charged HAp nanorods were assembled with the polycation poly-L-lysine (PLL) in LbL fashion. The successful deposition of alternating layers was confirmed by quartz-crystal microbalance with dissipation monitoring. The Voigtbased viscoelastic model demonstrated steady film growth where three PLL/HAp bilayers reached a thickness of $70 \mathrm{~nm}$. The bioactivity of [PLL/HAp $]_{3}$ was evaluated in vitro by following the formation of a mineralized hydroxyapatite layer in simulated body fluid (SBF). X-ray diffraction, energy-dispersive X-ray spectroscopy and scanning electron microscopy (SEM) demonstrated formation of a crystalline hydroxyapatite layer and complete surface coverage within 7 days. SaOs-2 osteoblasts-like cells attached to the mineralized surfaces and developed longer filopodia extensions when compared to non-mineralized samples. Our results showed that $[\mathrm{PLL} / \mathrm{HAp}]_{3}$ films are feasible osteoconductive coatings applicable to orthopedic implants and fixation devices.
\end{abstract}




\section{INTRODUCTION}

Current clinical practices for bone repair are dominated by autologous and allogeneic bone graft, which ensure the preservation of fundamental properties such as osteoconduction, osteoinduction, and osteogenesis. The success of such procedures is nonetheless limited: autografts are challenging to obtain due to donor site morbidity and necessity to do a second surgery, whereas allografts limitations emerge from the shortage of donors, risk of disease transmission and rejection. ${ }^{1-3}$ Moreover, there are no synthetic or heterologous bone substitutes available with the physical or biological properties as the original bone. ${ }^{4-6}$ As a consequence, the majority of critical bone defects are still unrecoverable and neither efficiently nor adequately treated.

The development of new biomaterials and processing routes of synthetic biomedical devices has been crucial to achieve enhanced bone repair. In this sense, the surface of an implant is the first contact established with the physiological environment: the events that take place at the surface of a new implant or a prosthetic device (e.g., proteins adsorption, ${ }^{7}$ osteoblast adhesion and proliferation $)^{8}$ are decisive to define whether there is osseointegration - the physical anchorage of the implant to the native bone - or device rejection by the host. It is thus essential that an implant surface exhibits good osteoinduction - the stimulation of progenitor cells into bone cells - as well as osteoconduction - the ability to promote mineralization and bone growth at the surface of the implant. ${ }^{9-11}$ Bioceramics are considered suitable biomaterials for bone repair because of their high osteoconductive capacity. Among them, hydroxyapatite (HAp) is the most common choice to develop synthetic substitutes due to its chemical composition that is similar to 
the mineral phase in the bone. In vivo, hydroxyapatite nucleation and mineral growth occurs within the extracellular matrix of cells and has the general formula $\mathrm{Ca}_{10}(\mathrm{OH})_{2}\left(\mathrm{PO}_{4}\right)_{6} \cdot{ }^{12-14}$ Calcium and phosphate concentrations between the implant and bone are augmented due to the dissolution of HAp from the implanted material, leading to precipitation and formation of a crystalline layer. Thus, HAp enhances the implant mineralization and induce the growth of a crystalline phase with shape, composition, and orientation that closely resemble the mineral phase of calcified tissues. ${ }^{15}$

HAp nanoparticles can be produced in different forms (e.g., spheres and needles) and in large amounts with controlled composition, size, and shape using relatively cheap synthetic approaches. ${ }^{16-19}$ Among different methodologies, microfluidic devices used for conventional nanoparticle syntheses offer several advantages such as reproducibility, stability, and versatility. These devices enable a high precision in the liquid handling, resulting in precise control of properties like shape, size, and morphology simply by modifying inherent physical factors such as the residence time, the capillary length and the flow rate. ${ }^{20-21}$ Furthermore, by using microfluidics, the costs can be notably reduced. ${ }^{22}$ Spherical particles are often the preferred HAp morphology choice, but in bone hydroxyapatite presents an elongated rod-like shape with dimensions about $50 \mathrm{~nm} \times 25 \mathrm{~nm} \times 4 \mathrm{~nm}$. Compared to spherical nanoparticles, nanorods showed higher surface-to-volume ratio and higher total amount of calcium ions released to solution. ${ }^{23-24}$

The immobilization of a HAp layer on the surface of implant/device that is in direct contact with body fluids and cells is of crucial importance for proper osseointegration. Herein we use layerby-layer (LbL) to coat surfaces with HAp nanomaterials. LbL is a straightforward and versatile bottom-up surface modification technique that can be applied to coat substrates with different 
geometries, from simple planar membranes to complex three-dimensional shapes. ${ }^{25-27}$ It consists of the consecutive deposition of different materials that are held together by supramolecular forces, such as electrostatic interactions, hydrogen bonding, and van der Walls forces. ${ }^{28}$ Its main advantage is the possibility for the incorporation of several classes of materials, including biomolecules and inorganic particles. The surfaces modified by LbL thus exhibit properties that are transferred from the incorporated building blocks. LbL versatility, together with the possibility to use aqueous solutions, makes this approach a mild and sustainable choice for bioactive surface buildup. ${ }^{29}$

In this work, we prepared LbL films by combining the polycation poly-L-lysine (PLL) and negatively charged HAp nanorods. The electrostatic interactions between PLL and the bioactive HAp nanorods result in a sequential hybrid nanocoating consisting of alternate layers of a biomacromolecule and a bioceramic. We hypothesize that the incorporated nanorods resemble not only structurally the inorganic phase of the bone but also biofunctionally, i.e. they will promote osteoinduction and osteoconduction..$^{30-31}$

\section{EXPERIMENTAL SECTION}

Materials and reagents. Hexadecyl-trimethylammonium bromide (CTAB), polypropylene glycol (PPG, molecular weight: $425 \mathrm{~g} \mathrm{~mol}^{-1}$, density: $1.004 \mathrm{~g} \mathrm{~cm}^{-3}$ at $25^{\circ} \mathrm{C}$ ), sodium phosphate, calcium chloride, sodium nitrite, poly-L-lysine hydrobromide (15-30 kDa), collagen (type I solution from rat tail), heparin sodium salt of porcine intestinal mucosa (grade I-A, $\geq 180$ USP units $/ \mathrm{mg}$ ) and phosphate buffered saline tablets (PBS) used for the synthesis of HAp nanorods and LbL assembly were purchased from Sigma-Aldrich and were used without further 
purification. Sodium chloride (LaborSpirit), sodium bicarbonate (Sigma-Aldrich), potassium chloride (VWR), dipotassium hydrogen phosphate trihydrate (VWR), magnesium chloride hexahydrate (Sigma-Aldrich), calcium chloride (VWR), sodium sulphate (LaborSpirit), tris(hydroxymethyl) aminomethane (Sigma-Aldrich), and hydrochloric acid (VWR) were used for the preparation of the simulated body fluid (SBF). Dulbecco's Modified Eagle's medium (DMEM, Sigma-Aldrich), MTS reagent (VWR), TrypLE Express (Alfagene), fetal bovine serum (FBS, Alfagene) DAPI (VWR), phalloidin (Sigma-Aldrich) and sodium bicarbonate (SigmaAldrich) were purchased for the cell culture and characterization. Gold-coated quartz crystals (QSX301) were obtained from Biolin Q-Sense (Sweden). Triple distilled water was used to prepare all solutions.

Microchip fabrication. The microfluidic devices were created by lithography. The mould was obtained by exposing a 2" diameter silicon wafer to oxygen plasma to clean its surface, and then spin coating it with an epoxy resin at $500 \mathrm{rpm}$ for $75 \mathrm{~s}$ to control the size of the channels (200 $\mu \mathrm{m})$. The solvent of the resin was removed by a pre-baking procedure carried out in a hot plate at $60{ }^{\circ} \mathrm{C}$ for $8 \mathrm{~min}$ and $95^{\circ} \mathrm{C}$ for $15 \mathrm{~min}$. When the resin solidified onto the substrate, a mask was placed and the resin was crosslinked by UV lamp $(365 \mathrm{~nm})$ for $4 \mathrm{~min}$.

Next, the substrate was submerged in propylene glycol monomethyl ether acetate (PGMEA) for $10 \mathrm{~min}$ in order to discard the non-exposed resin of the substrate. Then, to achieve a better robustness of the mould, it was baked at $135^{\circ} \mathrm{C}$ and $2 \mathrm{~h}$. Afterward, polydimethylsiloxane (PDMS) was inserted into the generated mould and left for $45 \mathrm{~min}$ in an oven at $60^{\circ} \mathrm{C}$ until complete solidification was achieved. Once the PDMS chips were obtained, the concluding step was to assemble them to the surface of microscopy slides. To do so, the surfaces of the slides were also covered with PDMS and cured. Then, both the chips and the slides were put in a 
plasma cleaner for $1 \mathrm{~min}$ to activate their surfaces. Once in contact, the microscope slides and the chips were merged correctly and consolidated, ending the process and obtaining the final microchips.

Synthesis of HAp nanorods. The HAp nanorods were synthesized by a microfluidic device consisting of two associated $\mathrm{Y}$-junction chips. The required aqueous solutions were pumped into the system through the following inlets: $\mathrm{A}\left(\mathrm{Na}_{3} \mathrm{PO}_{4}\right), \mathrm{B}\left(\mathrm{CaCl}_{2}\right), \mathrm{D}\left(\mathrm{NaNO}_{2}+\mathrm{CTAB}+\mathrm{PPG}\right)$

(Figure 1). Water was injected by inlet $\mathrm{C}$ to avoid obstruction and to improve the flow, effectively serving to drag the formed HAp through the channels. The initial solution concentrations were adapted from : $4 \mathrm{mM} \mathrm{CTAB,} 0.18 \mathrm{M} \mathrm{PPG}, 0.12 \mathrm{M} \mathrm{Na}_{3} \mathrm{PO}_{4}, 1.56 \mathrm{M} \mathrm{CaCl}_{2}$, and 1.56 $\mathrm{M} \mathrm{Na}_{3} \mathrm{PO}_{4}$, adapted from Liu et al ${ }^{32}$ and D'Elia et al. ${ }^{33}$ The inputs were attached to two syringe pumps (KDS 101 Legacy Syringe Pump) configured in such a way that allowed to maintain a precise and constant flow of $1.5 \mathrm{~mL} \mathrm{~h}^{-1}$ in each of the four syringes. The mixture obtained from the microfluidic system was purified following a thermal treatment to isolate the HAp nanorods from the salts and organic compounds derived from the micellar solution. It was placed in an autoclave at $100{ }^{\circ} \mathrm{C}$ for $24 \mathrm{~h}$ followed by filtration and washing the materials with distilled water to remove impurities. The material was then dried at $50{ }^{\circ} \mathrm{C}$ for $24 \mathrm{~h}$ and finally ignited in the muffle furnace for $3 \mathrm{~h}$ at about $400{ }^{\circ} \mathrm{C}$.

Structural characterization of HAp nanorods. Different techniques were used to characterize the produced nanostructures. Images of the nanorods were obtained by JEOL JEM-2010 transmission electron microscopy (TEM, Japan) with a $200 \mathrm{kV}$ ultrahigh resolution and ZEISS field emission scanning electron microscopy (FE-SEM) Ultra Plus (Germany). HAp nanorods were suspended in $10 \mathrm{~mL}$ of butanol, dispersed by sonication for $30 \mathrm{~min}$ and dropped onto $\mathrm{Cu}$ grids for TEM analysis. A dry HAp powder was placed onto grids and a secondary electron 
detector was used to capture the SEM images. The resolution (WD) was $2.1 \mathrm{~nm}$, and the accelerating voltage (EHT) was $3.00 \mathrm{kV}$. A Philips type powder diffractometer (Netherlands) fitted with a Philips "PW1710" control unit, a Vertical Philips "PW1820/00" goniometer, and FR590 Enraf Nonius generator was used for determination of X-ray powder diffraction pattern. The copper radiation source was $(\lambda(\mathrm{K} \alpha 1)=1.5406 \AA)$, working at $30 \mathrm{~mA}$ and $40 \mathrm{kV}$ was used. The counting time was $2 \mathrm{~s}$ per step, and the step size was $0.02^{\circ}$. The X-Ray powder diffraction pattern was determined by measuring the scintillation response to $\mathrm{Cu} \mathrm{K} \alpha$ radiation versus the $2 \Theta$ value over a $2 \Theta$ interval of $10-70$. The $\zeta$-potential was determined by operating a Malvern Zeta Sizer Nano ZS90 (United Kingdom) with a He-Ne laser $(\lambda=633 \mathrm{~nm})$. HAp nanorods were dispersed in water by sonication for $30 \mathrm{~min}$ and then analyzed. The $\zeta$-potential was calculated from electrophoretic mobility using the Henry equation (Eq. 1) and the Malvern`s ZetaSizer software (version 7.04):

$U_{E}=\frac{2 \varepsilon \zeta f(K a)}{3 \eta}$

where $\zeta$ is the zeta potential, $U_{e}$ is the electrophoretic mobility, $\varepsilon$ is the dielectric constant, $\eta$ is the viscosity of the sample and $f(K a)$ is the Henry's function related to the size of the electric double layer.

Monitoring LbL film assembly. A QSense E4 quartz crystal microbalance (Sweden) with dissipation monitoring system was used to follow up the adsorption of PLL and HAp nanorods at a fundamental oscillation frequency of $5 \mathrm{MHz}$ and its overtones $\left(3^{\text {rd }}, 5^{\text {th }}, 7^{\text {th }}, 9^{\text {th }}, 11^{\text {th }}\right.$ and $\left.13^{\text {th }}\right)$. LbL was assembled on gold-coated quartz crystals pre-cleaned by a consecutive immersion in acetone, ethanol, and isopropanol (ultrasound bath, $40^{\circ} \mathrm{C}, 5 \mathrm{~min}$ each). Afterward, the crystals were washed with distilled water, dried under an $\mathrm{N}_{2}$ flow and plasma treated with $\mathrm{UV}$ and $\mathrm{O}_{3}$. 
Clean crystals were placed in the QCM-D flow chambers. A dispersion of HAp nanorods ( 0.5 $\mathrm{mg} / \mathrm{mL})$ and a solution of PLL $(0.1 \mathrm{mg} / \mathrm{mL})$ were prepared separately using acetate buffer $(0.1$ $\mathrm{M}, \mathrm{pH}=4.00$ ). A constant flow rate of $50 \mu \mathrm{L} \mathrm{min}^{-1}$ at $25^{\circ} \mathrm{C}$ was used for the deposition of each layer. The build-up started with PLL injected into the flow chambers for 10 min aided by a peristaltic pump, followed by the HAp deposition until frequency $(F)$ and dissipation $(D)$ stabilized. All deposition steps were followed by a rinsing step with acetate buffer (10 $\mathrm{min})$ to remove loosely bound material. LbL constructs with three bilayers were obtained and abbreviated as $[\mathrm{PLL} / \mathrm{HAp}]_{3}$.

Estimation of the film thickness and mass. The thickness of the assembled films was estimated using the Voigt-based viscoelastic model, ${ }^{34}$ integrated into the Dfind software (version 1.1.2672.53037), based on Eqs. 2 and 3:

$\Delta F \approx-\frac{1}{2 \pi \rho_{0} h_{0}}\left\{\frac{\eta_{3}}{\delta_{3}}+\sum_{j=k}\left[h_{j} \rho_{j} \omega-2 h_{j}\left(\frac{\eta_{3}}{\delta_{3}}\right)^{2} \frac{\eta_{j} \omega^{2}}{\mu_{j}^{2}+\omega^{2} \eta_{j}^{2}}\right]\right\}$

$\Delta D \approx \frac{1}{2 \pi f \rho_{0} h_{0}}\left\{\frac{\eta_{3}}{\delta_{3}}+\sum_{j=k}\left[2 h_{j}\left(\frac{\eta_{3}}{\delta_{3}}\right)^{2} \frac{\mu_{j} \omega}{\mu_{j}^{2}+\omega^{2} \eta_{j}^{2}}\right]\right\}$

where $k$ is the number of thin viscoelastic layers, $\rho_{0}$ and $h_{0}$ are the density and thickness of the quartz crystal, $\rho_{3}$ is the density of liquid, $\eta_{3}$ is the viscosity of the bulk liquid, $\delta_{3}$ is the viscous penetration depth of the shear wave in the bulk liquid, $\mu$ is the elastic shear modulus of an overlayer, and $\omega$ is the angular frequency of the oscillation. The thickness was calculated from the $5^{\text {th }} 7^{\text {th }}$ and $9^{\text {th }}$ overtones, setting the liquid density and HAp layer densities to default (1000 g $\left.\mathrm{L}^{-1}\right)$, and PLL layer density to default hydrated protein $\left(1100 \mathrm{~g} \mathrm{~L}^{-1}\right)$. 
Mineralization studies. [PLL/HAp] $]_{3}$ films were prepared by dip coating on gold-coated quartz crystals keeping the deposition times obtained from the QCM-D measurements. The rinsing step was carried out in acetate buffer by a gentle agitation. After the assembly, each crystal with the deposited LbL was rinsed three times in ultrapure water and immersed in $15 \mathrm{ml}$ of SBF at 37 ${ }^{\circ} \mathrm{C} .{ }^{35}$ Samples were retrieved after $1,3,7$ and 14 days of immersion in SBF and analyzed as described below. Bare gold and $[\mathrm{PLL} / \mathrm{HAp}]_{3}$ as-produced films were immersed in PBS as a control for 14 days. All sample preparation and mineralization procedures were conducted in sterile conditions.

Surface characterization of the LbL films. Before any analysis, the samples were rinsed in ultrapure water three times and left drying overnight at room temperature. The elemental composition of $[\mathrm{PLL} / \mathrm{HAp}]_{3}$ films and assessment of the growth of the mineral phase of the constructs prior and after incubation in SBF for different time-points was performed with a JEOL JSM-6010 LV SEM with energy-dispersive X-ray spectroscopy (SEM-EDS, Japan). Zeiss Auriga Compact high-resolution field emission SEM (HR-SEM, Germany) was used for visualization of the typical cauliflower morphology of mineralized hydroxyapatite with higher magnifications (up to $10000 \times$ ) after 14 days of incubation in SBF.

In vitro cell culture. SaOs-2 cells were cultured in complete DMEM supplemented with $3.7 \mathrm{~g} \mathrm{~L}^{-1}$ sodium bicarbonate, $10 \% \mathrm{FBS}$ and $1 \%$ penicillin-streptomycin. SaOs-2 cells were routinely grown in $75 \mathrm{~cm}^{2}$ tissue culture flasks at $37{ }^{\circ} \mathrm{C}$ in a humidified air atmosphere of $5 \% \mathrm{CO}_{2}$ exchanging the medium every three days until confluency was reached. Cells were detached from the flasks using TrypLE Express and resuspended in serum-free DMEM. A $100 \mu \mathrm{L}$ cell suspension $\left(2 \times 10^{4}\right.$ cells $\left./ \mathrm{mL}\right)$ was added on each studied surface $\left(1.5 \mathrm{~cm}^{2}\right)$, namely bare gold, $[\mathrm{PLL} / \mathrm{HAp}]_{3}$ films, and films that were immersed in SBF for 7 days, placed in a 12-well plate. 
Additional $900 \mu \mathrm{L}$ of serum-free medium was added $3 \mathrm{~h}$ after the seeding to each well and incubated in a humidified air atmosphere $\left(5 \% \mathrm{CO}_{2}, 37^{\circ} \mathrm{C}, 3\right.$ days $)$.

Characterization of adhered cells. The samples were washed with PBS after culture for 3 days and then prepared for characterization. Cytoskeleton organization was visualized by fluorescence microscopy (AxioImager Z1M Zeiss, Germany). Cells were fixed with $10 \%$ formalin at $4{ }^{\circ} \mathrm{C}$ for 30 min, rinsed with PBS, and a phalloidin solution in PBS (500 $\mu \mathrm{L}, 1: 200)$ was added to each well to stain the actin filaments of the cells' cytoskeleton in red, left to react for $45 \mathrm{~min}$ at room temperature, followed by washing with PBS. The samples were then incubated in DAPI solution in PBS (500 $\mu \mathrm{L}, 1: 1000)$ for 5 min to stain double-stranded DNA of the nuclei in blue, washed with PBS and imaged. Adhered cells were quantified by analyzing representative fluorescence pictures using ImageJ software (NIH, version 1.46r). MTS assay was used to assess cell viability. The samples were incubated in a $600 \mu \mathrm{L}$ solution of MTS reagent in serum-free DMEM without phenol red (1:5) for $3 \mathrm{~h}$ at $37^{\circ} \mathrm{C}$. The absorbance was read at $490 \mathrm{~nm}$ in a BioTek Synergie HT microplate ELISA reader (USA) and was directly related to the number of live cells adhered to the films. HR-SEM was used to visualize the filopodia of the adherent cells on each substrate. The samples were dehydrated by a consecutive incubation in solutions with increasing ethanol: $\mathrm{H}_{2} \mathrm{O}$ proportions $(50: 50,70: 30,90: 10$ and 100:0). The dry samples were sputtered with gold and observed under HR-SEM with a magnification of $10000 \times$.

Statistical analysis. Values reported for MTS assay and cell count reflect means \pm standard deviation of triplicates. All values were analyzed by $t$-student statistical tests using GraphPad Prism 6.0 (GraphPad Software, Inc., USA). All results were considered statistically significant at $p$-value less than 0.05 . 


\section{RESULTS AND DISCUSSION}

HAp nanorods were obtained by a microfluidic device previously described by us. ${ }^{21}$ A solution of mixed micelles of CTAB/PPG was pumped into the microfluidic system to synthesize the material. The addition of the surfactant reduces the size of the nanoparticles as the CTAB and PPG form a micellar solution with a high degree of ionization. Above the critical micellar concentration, CTAB turns spherical micelles into rod-like shapes, constituting a template which gives HAp its final elongated shape. CTAB interacts with the $\mathrm{PO}_{4}^{-3}$ groups ${ }^{33}$ and then $\mathrm{Ca}^{2+}$ ions are attracted, thus initiating the nucleation of HAp crystals at the interface of the micelles.

Figure 1 shows a schematic representation of the complete microreactor-based system operation. Phosphate and calcium precursors are introduced by the A and B inlets respectively. The micellar solution is pumped through inlet $\mathrm{D}$, and in the second microreactor the mentioned ionic interactions and the reaction takes place.

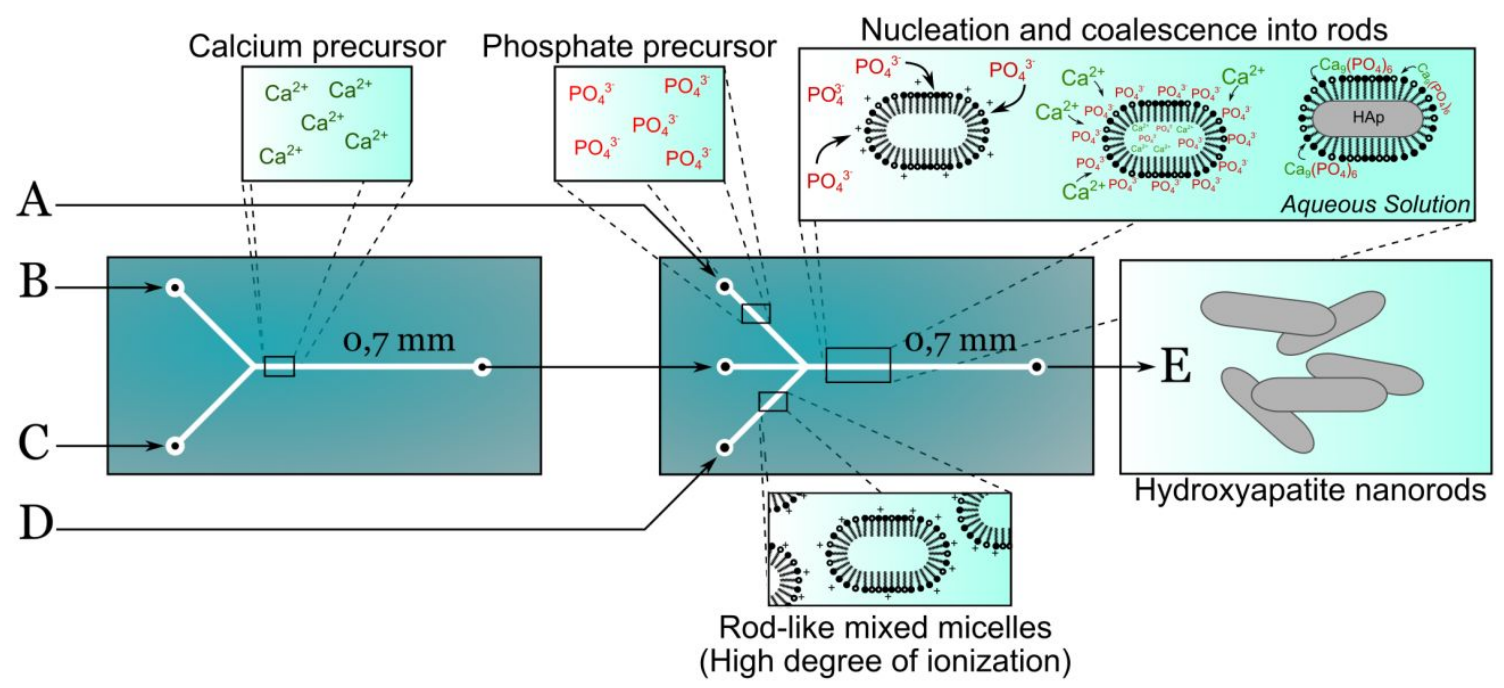

Figure 1. Schematic representation of the microfluidic system operation. 
Figure 2a shows the XRD analysis of the microfluidic generated HAp nanorods. The patterns agree with the bibliographical records for hexagonal $\mathrm{Ca}_{5}\left(\mathrm{PO}_{4}\right)_{3}(\mathrm{OH})$ (JCPDS file no. 9-432), and no impurities were detected. The XRD peaks are notably broad, which is consistent with the spectra for nanosized hydroxyapatite particles. ${ }^{32}$
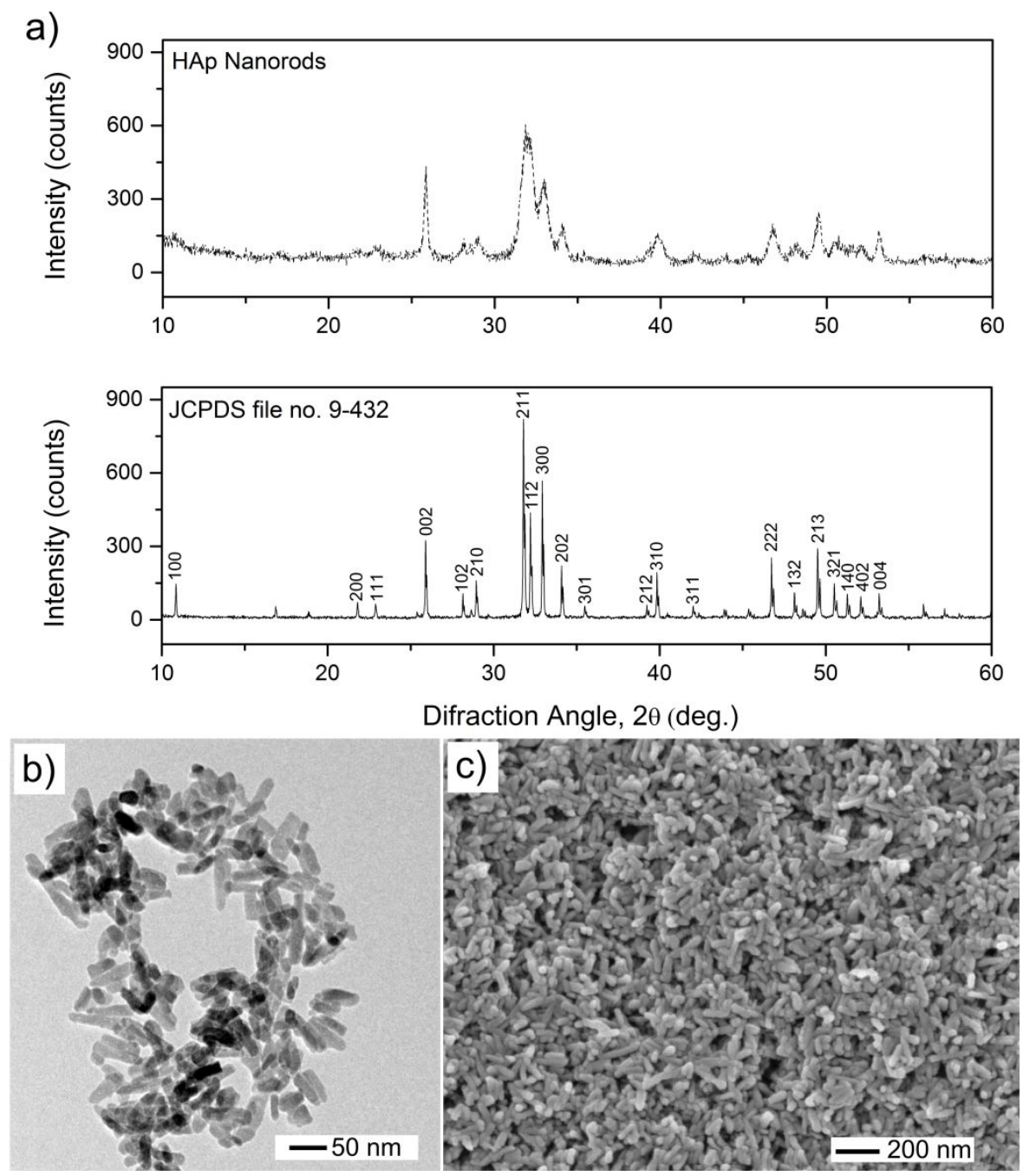

Figure 2. Characterization of the obtained hydroxyapatite nanorods by (a) X-ray diffraction pattern, (b) transmission electron microscopy and (c) scanning electron microscopy 
The fraction of crystalline phase was calculated from Eq. 4:

$X_{c}=1-\left(V 112 / 300 / I_{300}\right)$

where $I_{300}$ corresponds to the intensity (300) diffraction peaks and $V_{112 / 300}$ is the intensity of the hollow between (112) and (300) diffraction signals of HAp. The obtained value was 0.76 meaning that the sample had a feeble crystallinity, as is found in biogenic hydroxyapatite. Previous studies confirmed that the crystallinity of HAp is inversely related to the absorbability and the degree of bone resorption that take place at its surface. ${ }^{36-37}$ Given the XRD results, the synthesized HAp nanorods are promising materials to be introduced at the surface of biomedical devices intended for bone treatments.

HAp growth is restricted to the CTAB micellar surface and thus, we expected to obtain nanorods with a narrow size distribution corresponding to the CTAB micelles. Indeed, the TEM analysis (Figure 2b) confirmed that the material is formed by regular rod-like particles with similar aspect ratios and coincides with the expected size and resembles the elongation of hydroxyapatite crystals in bone. ${ }^{24}$ The ratio between the length and the diameter is also a decisive feature: the high length-to-diameter ratio of nanorods facilitate absorbability on the surface of the bone and can self-organize better than different morphologies to form a coating which can seal damaged surfaces over a broader area. ${ }^{38}$

SEM observations revealed that the nanorods had a tendency to aggregate, showing a random network pattern composed of profoundly agglomerated nanorods (Figure 2c, Figure S1). The size of the clumped nanoparticles is suggestive of being notably similar. The quantitative 
analysis of the images (Figure S2a) shows that the average size of the nanorods is $96 \mathrm{~nm}$ with a unimodal distribution, as was expected. ${ }^{32}$ In a previous work, SEM images were analyzed, trying to determine if the agglomeration had an ordered or arbitrary orientation. ${ }^{19}$ The distribution obtained for the HAp nanorods used herein demonstrated that their arrangement had a preference for a specific organization, following a bimodal distribution with main peaks centered at 43 and $139^{\circ}$ (Figure S2b). This fact denotes that the nanoparticle aggregation process is not isotropic but has favored alignments presumably associated with the shape and area of the nanorods. Apart from this, the ridged topography of the agglomerates may generate good anchoring points for osteoblastic cells to adhere. ${ }^{39}$

HAp exhibits $\mathrm{Ca}^{2+}$ and $\mathrm{PO}_{4}{ }^{3-}$ on its surface, which can act as adsorption sites for electrostatic proteins. ${ }^{40} \mathrm{HAp}$ nanorods dispersed in water have $\zeta$-potential of $-14 \mathrm{mV}$ and is consistent with previous studies. ${ }^{41}$ This negative $\zeta$-potential suggested that HAp nanorods can interact with cationic polypeptides via electrostatic interactions. Real time by QCM-D (Figure 3) was used to confirm this hypothesis. This equipment allows detection of adsorption of small amounts of material (in the order of nanograms per square centimeter) to a gold-coated quartz sensor. ${ }^{42-44}$ In QCM-D, the quartz crystals are exposed to acoustic excitation and oscillate as a result. The oscillation frequency is related to the quantity of adsorbed materials and quantification of frequency changes upon contact with a solute are used to determine whether deposition occurs. 
a)

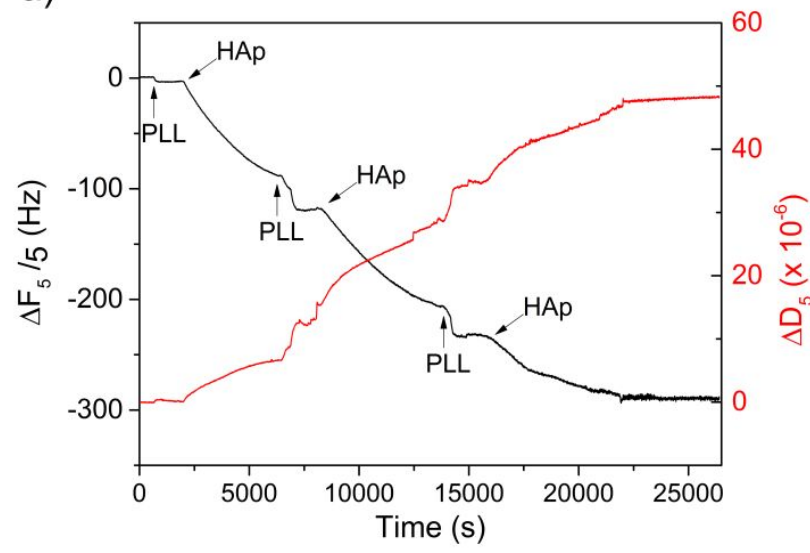

b)

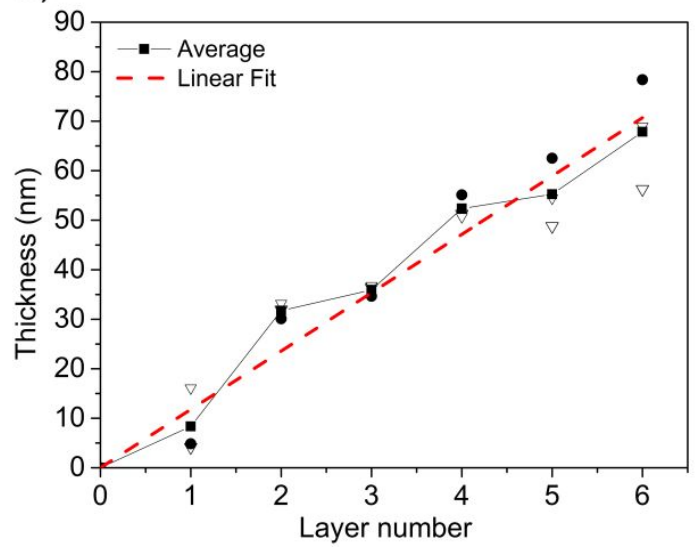

Figure 3. a) Representative normalized variations of frequency $\left(\Delta F_{n} / n\right)$ and dissipation $\left(\Delta D_{n}\right)$ for the $5^{\text {th }}$ overtone during the assembly of $[\mathrm{PLL} / \mathrm{HAp}]_{3}$ films. b) Thickness growth of the $[\mathrm{PLL} / \mathrm{HAp}]_{3}$ films calculated from the Voigt-based viscoelastic model (black) and data fitting (red) showing linear growth of the LbL construct. Three independent experiments are depicted.

The continuous decrease in $\Delta F_{5} / 5$ with each incremental deposition step confirms successful LbL buildup (Figure 3a). Changes in dissipation are related with variations of the viscoelastic properties of the formed construct: high dissipation indicates viscous behavior and damping, associated with the assembly of "soft" films. Likewise, a decrease in $\Delta D_{5}$ is typical of structural transformation from a dissipative nonrigid surface to a stiffer one. Herein, $\Delta D_{5}$ increases with each incremental layer, including during the adsorption of the HAp nanorods. One would expect that the adsorption of a ceramic material would increase the stiffness of the films, but the results suggest presence of interfacial hydration layers on the surface of HAp. ${ }^{45}$ Such a layer appears mainly constituted by $\mathrm{H}_{2} \mathrm{O}$ molecules coordinated to superficial $\mathrm{Ca}^{2+}$ ions approximately in a $1: 1$ ratio. ${ }^{46}$ The film thickness (Figure 3b) increased linearly during the buildup. After the adsorption of 3 bilayers, a thickness of $67 \mathrm{~nm}$ was obtained, which corresponds to a total area 
density of $7.8 \mu \mathrm{g} \mathrm{cm}^{-2}$. Of note, the film growth was higher during the adsorption of HAp nanorods (Figure 3a). This is due to the contribution of the above mentioned interfacial hydration layers, which translates into more film mass per surface area than their more flexible polycationic macromolecular counterparts. It is also noteworthy how HAp nanorods were easily intercalated with the macromolecular compound. Previous experiments with Bioglass ${ }^{\circledR}$ nanospheres required the use of additional polyanion layers to form stable LbLs as the charge of the inorganic material was not sufficient to build a stable construct. ${ }^{30-31}$

The osteoconductive potential of HAp-embedded LbL films was evaluated by immersion of the constructs in SBF (Figure 4). 
a)



b)

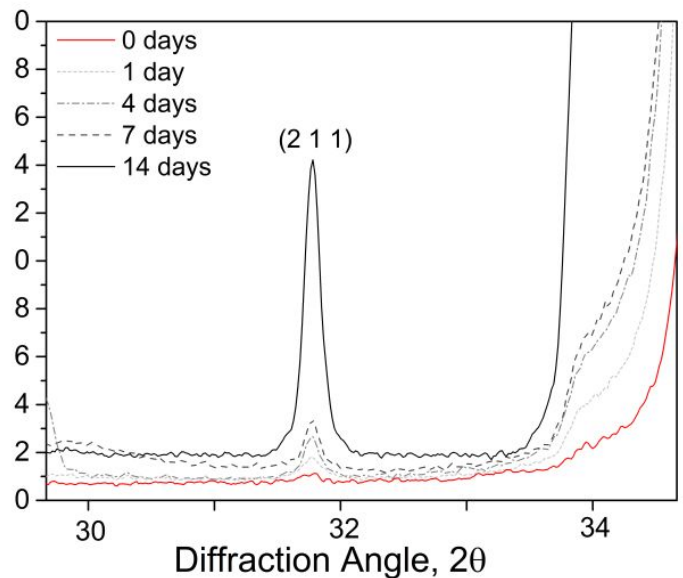

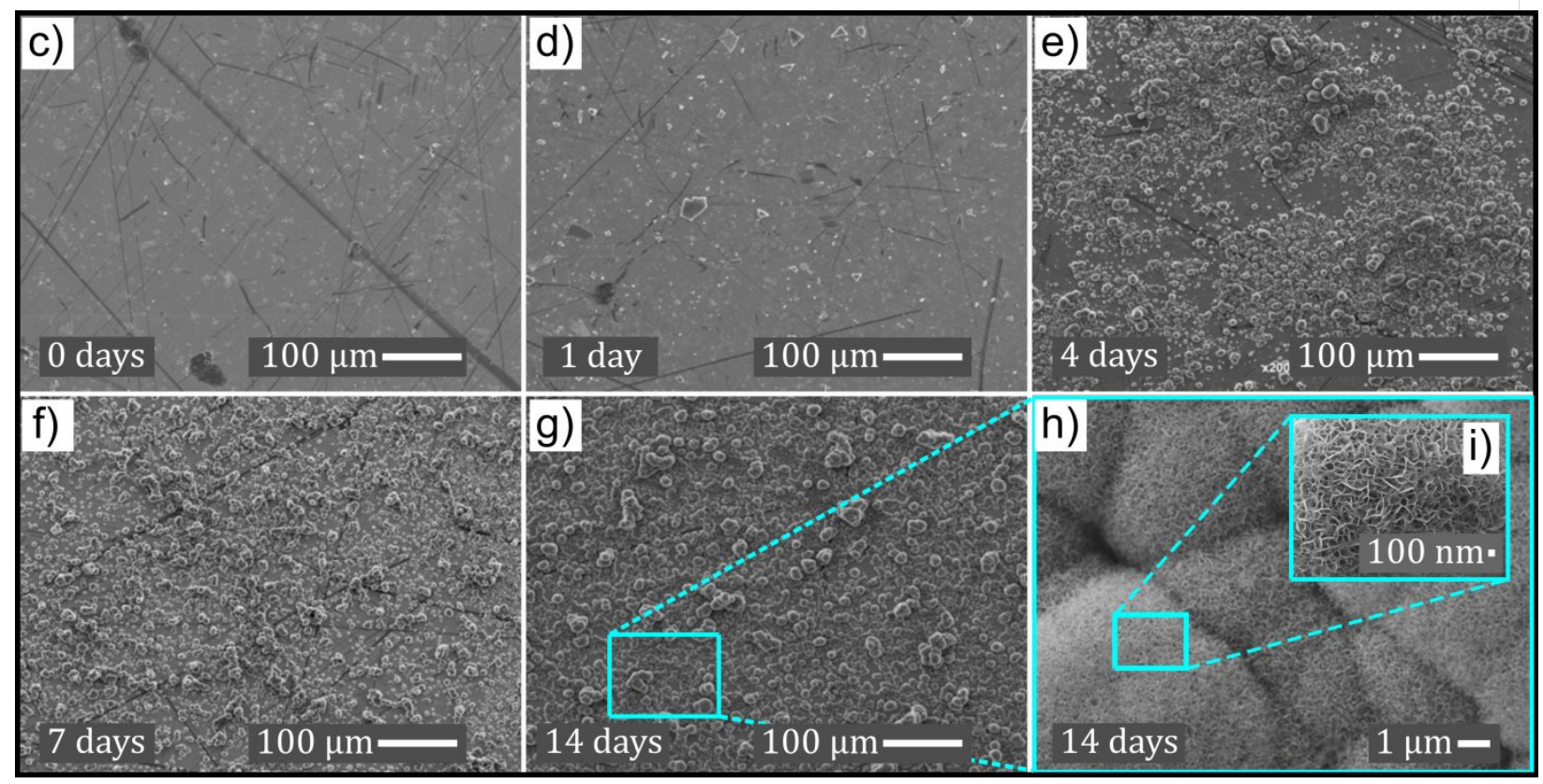

Figure 4. Mineralization assessment of $[\mathrm{PLL} / \mathrm{HAp}]_{3}$ films. (a) QCM-D measurements of dissipation for the $5^{\text {th }}$ overtone. Data fitting depicts a logarithmic approximation (red). (b) XRD spectra of the LbL constructs after 1, 4, 7 and 14 days of immersion in SBF. XRD spectra were treated to remove the strong diffraction signals produced by gold and quartz. (c-i) Scanning electron microscopy of the assembled films after $0,1,4,7$ and 14 days in SBF. The lines in (c) and (d) are artifacts from defects on the gold surface. (h, i) High-resolution field emission scanning electron microscopy with different magnifications up to 14 days. 
The $\Delta D_{n}$ of the films increased as time progressed. Significant increases were produced up to the seventh day, after which the variation was less pronounced (Figure 4a). The rise in dissipation is consistent with the formation of interfacial hydration layers which are coupled to the nucleation and growth of a mineral hydroxyapatite phase over time. ${ }^{24}$ Apatite crystallization is associated with a decrease in the Gibbs free energy as a result of the electrostatic interactions that induce calcium and phosphate nucleation. ${ }^{47}$ Mineralization starts with a complex process of initial nuclei formation and growth. There are different theories explaining this phenomenon. Works from Rodríguez Clemente et al. ${ }^{48}$ and López Macipe et al. ${ }^{49}$ have described the crystallization route of hydroxyapatite at $37^{\circ} \mathrm{C}$ as the result of the coexistence of the amorphous calcium phosphate and octacalcium phosphate precursors in the mineralization solutions. Furthermore, Takadama et al. ${ }^{50}$ have reported that an amorphous calcium phosphate initially forms during the nucleation stage and then mutates to a crystalline apatite. X-ray diffraction was used to analyze the crystallinity of the mineralized phase (Figure $\mathbf{4 b}$ ). Information about the development of the mineralization progress was obtained by the reflection specific to the apatite phase $((211)[2 \Theta=$ 31.8 degrees]). The intensity of this peak increased over time, getting to the highest value after 14 days of mineralization. This increase showcases the formation of crystalline hydroxyapatite similar to the ones found in natural bone. Furthermore, as it can be inferred from the SEM images (Figure 4c-i, Figure S3), the mineralization of [PLL/HAp $]_{3}$ films started to manifest notoriously after the fourth day of immersion in SBF. After 14 days, the surface was entirely covered by a mineral layer with the typical cauliflower-like morphology of apatite layers. Thus, the in vitro formation of HAp layer by SBF demonstrated that $[\mathrm{PLL} / \mathrm{HAp}]_{3}$ films are osteoconductive. 
The QCM-D, XRD and SEM results are in good agreement with the EDS analysis (Table S1). On the one hand and as expected, the $\mathrm{Ca}$ and $\mathrm{P}$ presence in the samples increased gradually as the mineralization progressed. On the other hand, surfaces mineralized for 14 days exhibited a $\mathrm{Ca} / \mathrm{P}$ ratio of 1.91 . As mentioned above, $\mathrm{ACP}$ is a precursor phase that precedes the formation of crystalline hydroxyapatite in a supersaturated calcium phosphate solution. ACP particles consist of a random assembly of ion clusters, with a $\mathrm{Ca} / \mathrm{P}$ molar ratio of about 1.2 compared to the ratio of 1.67 found in stoichiometric hydroxyapatite. ${ }^{51}$ The ratio of 1.91 determined for the studied LbL is higher than either of these values, suggesting that, in addition to calcium phosphate, calcium oxide $(\mathrm{CaO})$ is forming as well. Previous studies have demonstrated that higher $\mathrm{Ca} / \mathrm{P}$ ratios induce increased osteoblast adhesion, ${ }^{52}$ but can also lower osteoblast viability. ${ }^{53}$ Cells response towards the substrate is paramount to develop bone/biomaterial interfaces, as the adhesion of cells to biomedical devices and their viability is an essential factor in defining biological compliance.

SaOs-2 osteoblast-like cells were chosen to evaluate the cytotoxicity of [PLL/HAp $]_{3}$ envisaging the use of these films as mineralizing coatings for implantable devices that will interface with bone. Cells were cultured in contact with $[\mathrm{PLL} / \mathrm{HAp}]_{3}$ films and $[\mathrm{PLL} / \mathrm{HAp}]_{3}$ films incubated for 7 days in SBF. This period of mineralization was chosen based on the hydroxyapatite layer growth (Figure 4). After 3 days of culture, the number of osteoblasts adhered to the substrates and their viability was assessed (Figure 5, Figure S4). The number of adherent cells (Figure 5a) and cell viability (Figure 5b) was similar for both substrates. However, microscopy observation evidenced clear morphological differences (Figure 5c-f). Staining the cytoskeleton with phalloidin showed that the cells adhered to mineralized substrates were more elongated than cells on $[\mathrm{PLL} / \mathrm{HAp}]_{3}$ films. HR-SEM images confirmed the formation of filopodia extensions from 
osteoblasts adherent on both substrates, though these cytoplasmic projections were more numerous, longer, and branched in the SaOs-2 cells cultured on mineralized surfaces as compared with the pristine ones. The abundance of long filopodia with lateral protrusions is in agreement with the response of osteoblastic cells to surfaces engineered to promote high spreading and strength of adhesion. ${ }^{54-55}$ With more developed filopodia from SaOs-2 cells on our mineralized films, we confirm that their resemblance with the crystalline hydroxyapatite promote a more intimate contact of osteoblasts than on non-mineralized $[\mathrm{PLL} / \mathrm{HAp}]_{3}$ films.

a)
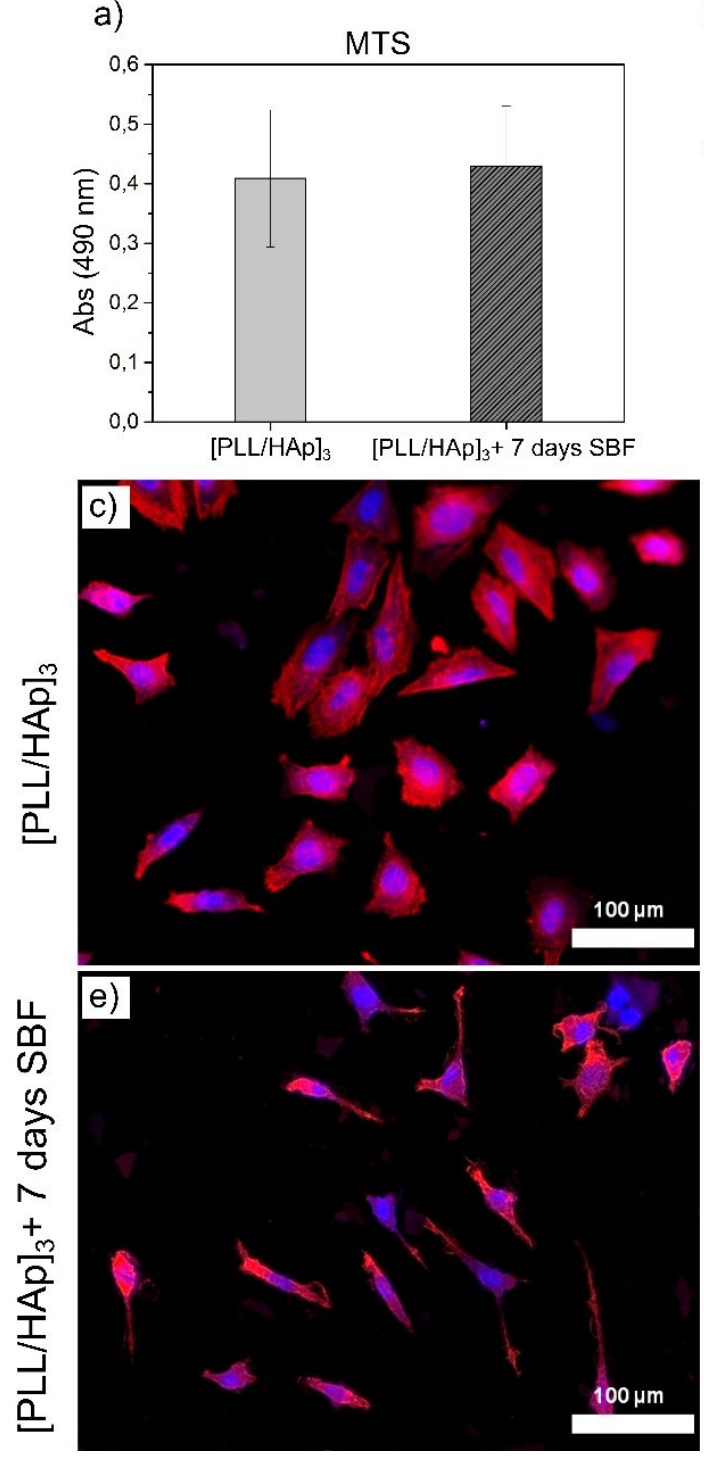

b)
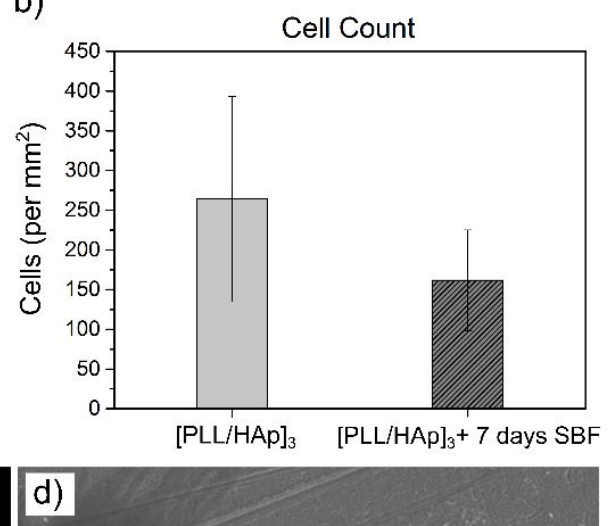
$1 \mu \mathrm{m}$

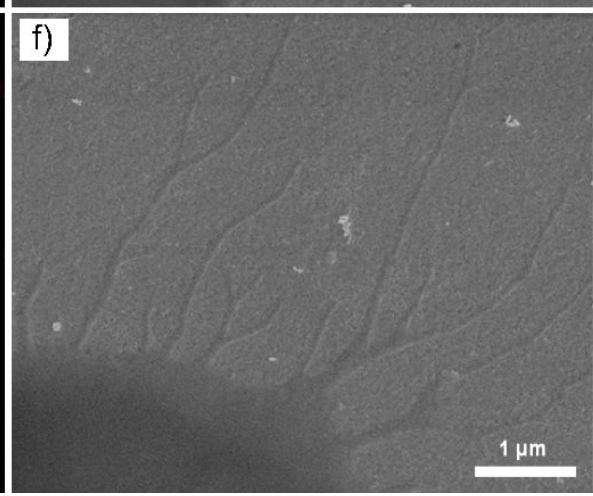


Figure 5. SaOs-2 osteoblast-like cells cultured on $[\mathrm{PLL} / \mathrm{HAp}]_{3}$ and mineralized $[\mathrm{PLL} / \mathrm{HAp}]_{3}$ : (a) number of adherent cells and (b) their viability on [PLL/HAp $]_{3}$ before and after 7 days of mineralization; Data are means \pm standard deviation $(p>0.05)$. (c, e) Representative fluorescence microscopy micrographs showing cytoskeletal organization of SaOs-2 cells after 3 days of culture in contact with the studied substrates (nuclei stained in blue with DAPI and actin filaments in the cytoskeleton in red with phalloidin). (d, f) SEM images of SaOs-2 showing formation of filopodia with different lengths in response to the underlaying substrate.

\section{CONCLUSIONS}

We have developed a unique composite design to create a biomaterial interface that mimics the properties of natural bone by coupling ceramic layers with soft matter ones. The increase of the HAp surface area resulting from the elongated shape of the nanorods as compared to spherical formulations enhances the electrostatic interactions with polycations and make possible LbL build up. This class of LbLs are suitable for coating of implantable devices as they are osteoconductive and support cell adhesion, spreading and viability, opening a whole new range of possibilities to create a biocompatible interface for implantable systems targeting regeneration of bone tissue.

\section{ASSOCIATED CONTENT}

Supporting Information. The following files are available free of charge: Additional SEM images of HAp nanorods (Figure S1, PDF); SEM size and angle distribution (Figure S2, PDF); SEM of [PLL/HAp $]_{3}$ films and bare gold substrates after 14 days of incubation in PBS (Figure 
S3, PDF); EDS for the composition of [PLL/HAp $]_{3}$ films up to 14 days of incubation in SBF

(Table S1, PDF); Number of cells and viability against gold substrate controls (Figure S4, PDF).

\title{
AUTHOR INFORMATION
}

\section{Corresponding Author}

*Iva Pashkuleva: pashkuleva@i3bs.uminho.pt

*Juan M. Ruso: juanm.ruso@usc.es

\section{Author Contributions}

The manuscript was written through contributions of all authors. All authors have given approval to the final version of the manuscript. \#These authors contributed equally.

\author{
ACKNOWLEDGMENT \\ The authors acknowledge Fundación Ramón Areces, Xunta de Galicia (ED431B 2017/21, \\ ED41E2018/08), Programa Iacobus, financial support from "Fundação para a Ciência e \\ Tecnologia" (grant CEECIND/02842/2017 to R. R. C. and project Norte-01-0145-FEDER- \\ 022190) and the EC H2020 programme through the projects ELASTISLET (NMP-2014- \\ 646075).
}

\section{REFERENCES}

(1) Baldwin, P.; Li, D. J.; Auston, D. A.; Mir, H. S.; Yoon, R. S.; Koval, K. J., Autograft, Allograft, and Bone Graft Substitutes: Clinical Evidence and Indications for Use in the Setting of Orthopaedic Trauma Surgery. J. Orthop. Trauma 2019, 33, 203-213.

(2) García-Gareta, E.; Coathup, M. J.; Blunn, G. W., Osteoinduction of bone grafting materials for bone repair and regeneration. Bone 2015, 81, 112-121. 
(3) Giannoudis, P. V.; Dinopoulos, H.; Tsiridis, E., Bone substitutes: An update. Injury 2005, 36, S20-S27.

(4) Agarwal, R.; García, A. J., Biomaterial strategies for engineering implants for enhanced osseointegration and bone repair. Adv. Drug Delivery Rev. 2015, 94, 53-62.

(5) Dimitriou, R.; Jones, E.; McGonagle, D.; Giannoudis, P. V., Bone regeneration: current concepts and future directions. BMC Med. 2011, 9, 66.

(6) Loi, F.; Córdova, L. A.; Pajarinen, J.; Lin, T.-h.; Yao, Z.; Goodman, S. B., Inflammation, fracture and bone repair. Bone 2016, 86, 119-130.

(7) Wilson, C. J.; Clegg, R. E.; Leavesley, D. I.; Pearcy, M. J., Mediation of Biomaterial-Cell Interactions by Adsorbed Proteins: A Review. Tissue Eng. 2005, 11, 1-18.

(8) Ducheyne, P.; Qiu, Q., Bioactive ceramics: the effect of surface reactivity on bone formation and bone cell function. Biomaterials 1999, 20, 2287-2303.

(9) Weber, F. E., Reconsidering osteoconduction in the era of additive manufacturing. Tissue Engineering Part B: Reviews 2019, in press, DOI: 10.1089/ten.TEB.2019.0047.

(10) Martin, V.; Bettencourt, A., Bone regeneration: Biomaterials as local delivery systems with improved osteoinductive properties. Mater. Sci. Eng., C 2018, 82, 363-371.

(11) Albrektsson, T.; Johansson, C., Osteoinduction, osteoconduction and osseointegration. Eur. Spine J. 2001, 10, S96-S101.

(12) Doi, Y.; Shibutani, T.; Moriwaki, Y.; Kajimoto, T.; Iwayama, Y., Sintered Carbonate as Resorbable Bone Substitutes. 1998; Vol. 39, p 603-610. 
(13) Fihri, A.; Len, C.; Varma, R. S.; Solhy, A., Hydroxyapatite: A review of syntheses, structure and applications in heterogeneous catalysis. Coord. Chem. Rev. 2017, 347, 48-76.

(14) Yi, H.; Ur Rehman, F.; Zhao, C.; Liu, B.; He, N., Recent advances in nano scaffolds for bone repair. Bone Res. 2016, 4, 16050.

(15) Zhou, H.; Lee, J., Nanoscale hydroxyapatite particles for bone tissue engineering. Acta Biomater. 2011, 7, 2769-2781.

(16) Lebre, F.; Sridharan, R.; Sawkins, M. J.; Kelly, D. J.; O’Brien, F. J.; Lavelle, E. C., The shape and size of hydroxyapatite particles dictate inflammatory responses following implantation. Sci. Rep. 2017, 7, 2922.

(17) Luo, P.; Nieh, T. G., Preparing hydroxyapatite powders with controlled morphology. Biomaterials 1996, 17, 1959-1964.

(18) Zhang, C.; Yang, J.; Quan, Z.; Yang, P.; Li, C.; Hou, Z.; Lin, J., Hydroxyapatite Nanoand Microcrystals with Multiform Morphologies: Controllable Synthesis and Luminescence Properties. Cryst. Growth Des. 2009, 9, 2725-2733.

(19) Rial, R.; Tichnell, B.; Latimer, B.; Liu, Z.; Messina, P. V.; Ruso, J. M., Structural and Kinetic Visualization of the Protein Corona on Bioceramic Nanoparticles. Langmuir 2018, 34, $2471-2480$.

(20) Liu, D.; Cito, S.; Zhang, Y.; Wang, C.-F.; Sikanen, T. M.; Santos, H. A., A Versatile and Robust Microfluidic Platform Toward High Throughput Synthesis of Homogeneous Nanoparticles with Tunable Properties. Adv. Mater. 2015, 27, 2298-2304. 
(21) Rial, R.; Tahoces, P. G.; Hassan, N.; Cordero, M. L.; Liu, Z.; Ruso, J. M., Noble microfluidic system for bioceramic nanoparticles engineering. Mater. Sci. Eng., C 2019, 102, 221-227.

(22) Hassan, N.; Oyarzun-Ampuero, F.; Lara, P.; Guerrero, S.; Cabuil, V.; Abou Hassan, a.; Kogan, M., Flow Chemistry to Control the Synthesis of Nano and Microparticles for Biomedical Applications. 2014; Vol. 14.

(23) Jin, X.; Zhuang, J.; Zhang, Z.; Guo, H.; Tan, J., Hydrothermal synthesis of hydroxyapatite nanorods in the presence of sodium citrate and its aqueous colloidal stability evaluation in neutral pH. J. Colloid Interface Sci. 2015, 443, 125-130.

(24) Zhan, J.; Tseng, Y.-H.; Chan, J. C. C.; Mou, C.-Y., Biomimetic Formation of Hydroxyapatite Nanorods by a Single-Crystal-to-Single-Crystal Transformation. Adv. Funct. Mater. 2005, 15, 2005-2010.

(25) Costa, R. R.; Mano, J. F., Polyelectrolyte multilayered assemblies in biomedical technologies. Chem. Soc. Rev. 2014, 43, 3453-3479.

(26) Hammond, P. T., Engineering materials layer-by-layer: Challenges and opportunities in multilayer assembly. AIChE J. 2011, 57, 2928-2940.

(27) Liu, X. Q.; Picart, C., Layer-by-Layer Assemblies for Cancer Treatment and Diagnosis. Adv. Mater. 2016, 28, 1295-1301.

(28) Borges, J.; Mano, J. F., Molecular Interactions Driving the Layer-by-Layer Assembly of Multilayers. Chem. Rev. 2014, 114, 8883-8942. 
(29) Richardson, J. J.; Björnmalm, M.; Caruso, F., Technology-driven layer-by-layer assembly of nanofilms. Science 2015, 348, aaa2491.

(30) Rego, S. J.; Vale, A. C.; Luz, G. M.; Mano, J. F.; Alves, N. M., Adhesive Bioactive Coatings Inspired by Sea Life. Langmuir 2016, 32, 560-568.

(31) Rodrigues, J. R.; Alves, N. M.; Mano, J. F., Biomimetic polysaccharide/bioactive glass nanoparticles multilayer membranes for guided tissue regeneration. $R S C A d v \mathbf{2 0 1 6}, 6,75988$ 75999.

(32) Liu, Y.; Wang, W.; Zhan, Y.; Zheng, C.; Wang, G., A simple route to hydroxyapatite nanofibers. Mater. Lett. 2002, 56, 496-501.

(33) D'Elía, N. L.; Gravina, A. N.; Ruso, J. M.; Laiuppa, J. A.; Santillán, G. E.; Messina, P. V., Manipulating the bioactivity of hydroxyapatite nano-rods structured networks: Effects on mineral coating morphology and growth kinetic. Biochim Biophys Acta Gen Subj. 2013, 1830, 5014-5026.

(34) Voinova, M. V.; Rodahl, M.; Jonson, M.; Kasemo, B., Viscoelastic Acoustic Response of Layered Polymer Films at Fluid-Solid Interfaces: Continuum Mechanics Approach. Phys. Scr. 1999, 59, 391.

(35) Kokubo, T.; Takadama, H., How useful is SBF in predicting in vivo bone bioactivity? Biomaterials 2006, 27, 2907-2915.

(36) Carter, D. C.; Ho, J. X., Structure of Serum Albumin. In Advances in Protein Chemistry, C.B. Anfinsen, J. T. E. F. M. R.; David, S. E., Eds. Academic Press: 1994; Vol. Volume 45, pp 153-203. 
(37) Okazaki, M.; Moriwaki, Y.; Aoba, T.; Doi, Y.; Takahashi, J., Solubility behavior of CO3 apatites in relation to crystallinity. Caries Res. 1981, 15, 477-483.

(38) Padmanabhan, S. K.; Balakrishnan, A.; Chu, M.-C.; Lee, Y. J.; Kim, T. N.; Cho, S.-J., Sol-gel synthesis and characterization of hydroxyapatite nanorods. Particuology 2009, 7, 466470.

(39) Uskoković, V.; Batarni, S. S.; Schweicher, J.; King, A.; Desai, T. A., Effect of Calcium Phosphate Particle Shape and Size on Their Antibacterial and Osteogenic Activity in the Delivery of Antibiotics in Vitro. ACS Appl. Mater. Interfaces 2013, 5, 2422-2431.

(40) Cummings, L. J.; Snyder, M. A.; Brisack, K., Protein chromatography on hydroxyapatite columns. Methods Enzymol. 2009, 463, 387-404.

(41) Cai, Y.; Liu, Y.; Yan, W.; Hu, Q.; Tao, J.; Zhang, M.; Shi, Z.; Tang, R., Role of hydroxyapatite nanoparticle size in bone cell proliferation. J. Mater. Chem. 2007, 17, 3780-3787.

(42) Marx, K. A., Quartz Crystal Microbalance: A Useful Tool for Studying Thin Polymer Films and Complex Biomolecular Systems at the Solution-Surface Interface. Biomacromolecules 2003, 4, 1099-1120.

(43) Roach, P.; Farrar, D.; Perry, C. C., Interpretation of Protein Adsorption: Surface-Induced Conformational Changes. J. Am. Chem. Soc. 2005, 127, 8168-8173.

(44) Tamerler, C.; Oren, E. E.; Duman, M.; Venkatasubramanian, E.; Sarikaya, M., Adsorption Kinetics of an Engineered Gold Binding Peptide by Surface Plasmon Resonance Spectroscopy and a Quartz Crystal Microbalance. Langmuir 2006, 22, 7712-7718. 
(45) Zahn, D.; Hochrein, O., Computational study of interfaces between hydroxyapatite and water. Phys. Chem. Chem. Phys. 2003, 5, 4004-4007.

(46) Bertinetti, L.; Tampieri, A.; Landi, E.; Ducati, C.; Midgley, P. A.; Coluccia, S.; Martra, G., Surface Structure, Hydration, and Cationic Sites of Nanohydroxyapatite: UHR-TEM, IR, and Microgravimetric Studies. J. Phys. Chem. C 2007, 111, 4027-4035.

(47) Xie, Y.; Liu, X.; Chu, P. K.; Ding, C., Nucleation and growth of calcium-phosphate on Ca-implanted titanium surface. Surf. Sci. 2006, 600, 651-656.

(48) Rodríguez-Clemente, R.; López-Macipe, A.; Gómez-Morales, J.; Torrent-Burgués, J.; Castaño, V. M., Hydroxyapatite precipitation: A case of nucleation-aggregation-agglomerationgrowth mechanism. J. Eur. Ceram. Soc. 1998, 18, 1351-1356.

(49) Anabel, L. M.; Jaime, G. M.; Rafael, R. C., Nanosized Hydroxyapatite Precipitation from Homogeneous Calcium/Citrate/Phosphate Solutions Using Microwave and Conventional Heating. Adv. Mater. 1998, 10, 49-53.

(50) Takadama, H.; Kim, H.-M.; Miyaji, F.; Kokubo, T.; Nakamura, T., Mechanism of Apatite Formation Induced by Silanol Groups-TEM Observation. 2000; Vol. 108, p 118-121.

(51) Yun, J.; Holmes, B.; Fok, A.; Wang, Y., A Kinetic Model for Hydroxyapatite Precipitation in Mineralizing Solutions. Cryst. Growth Des. 2018, 18, 2717-2725.

(52) Ergun, C.; Liu, H.; Webster, T. J.; Olcay, E.; Yılmaz, Ş.; Sahin, F. C., Increased osteoblast adhesion on nanoparticulate calcium phosphates with higher $\mathrm{Ca} / \mathrm{P}$ ratios. J. Biomed. Mater. Res. A 2008, $85 A, 236-241$. 
(53) Liu, H.; Yazici, H.; Ergun, C.; Webster, T. J.; Bermek, H., An in vitro evaluation of the $\mathrm{Ca} / \mathrm{P}$ ratio for the cytocompatibility of nano-to-micron particulate calcium phosphates for bone regeneration. Acta Biomater. 2008, 4, 1472-1479.

(54) Guadarrama Bello, D.; Fouillen, A.; Badia, A.; Nanci, A., A nanoporous titanium surface promotes the maturation of focal adhesions and formation of filopodia with distinctive nanoscale protrusions by osteogenic cells. Acta Biomater. 2017, 60, 339-349.

(55) Salido, M.; Vilches, J. I.; Gutierrez, J. L.; Vilches, J., Actin cytoskeletal organization in human osteoblasts grown on different dental titanium implant surfaces. Histol. Histopathol. 2007, 22, 1355-1364. 


\section{FOR TABLE OF CONTENTS USE ONLY}

\section{Mineralization of layer-by-layer ultrathin films containing microfluidic-produced hydroxyapatite nanorods}

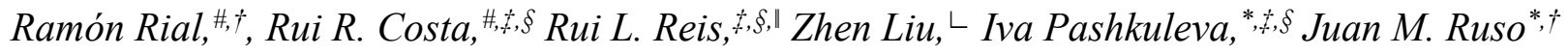

$\uparrow$ Soft Matter and Molecular Biophysics Group, Department of Applied Physics, University of Santiago de Compostela, 15782, Santiago de Compostela, Spain

$\$ 3$ B's Research Group, I3Bs - Research Institute on Biomaterials, Biodegradables and Biomimetics, University of Minho, Headquarters of the European Institute of Excellence on Tissue Engineering and Regenerative Medicine, AvePark, Parque de Ciência e Tecnologia, Zona Industrial da Gandra, 4805-017 Barco, Guimarães, Portugal

§ ICVS/3B's, PT Government Associated Laboratory, Braga/Guimarães, Portugal

" The Discoveries Centre for Regenerative and Precision Medicine, Headquarters at University of Minho, Avepark, 4805-017 Barco, Guimarães, Portugal

$\llcorner$ Department of Physics and Engineering, Frostburg State University, Frostburg, Maryland 21532, United States. 


\section{TOC GRAPHIC (ABSTRACT)}

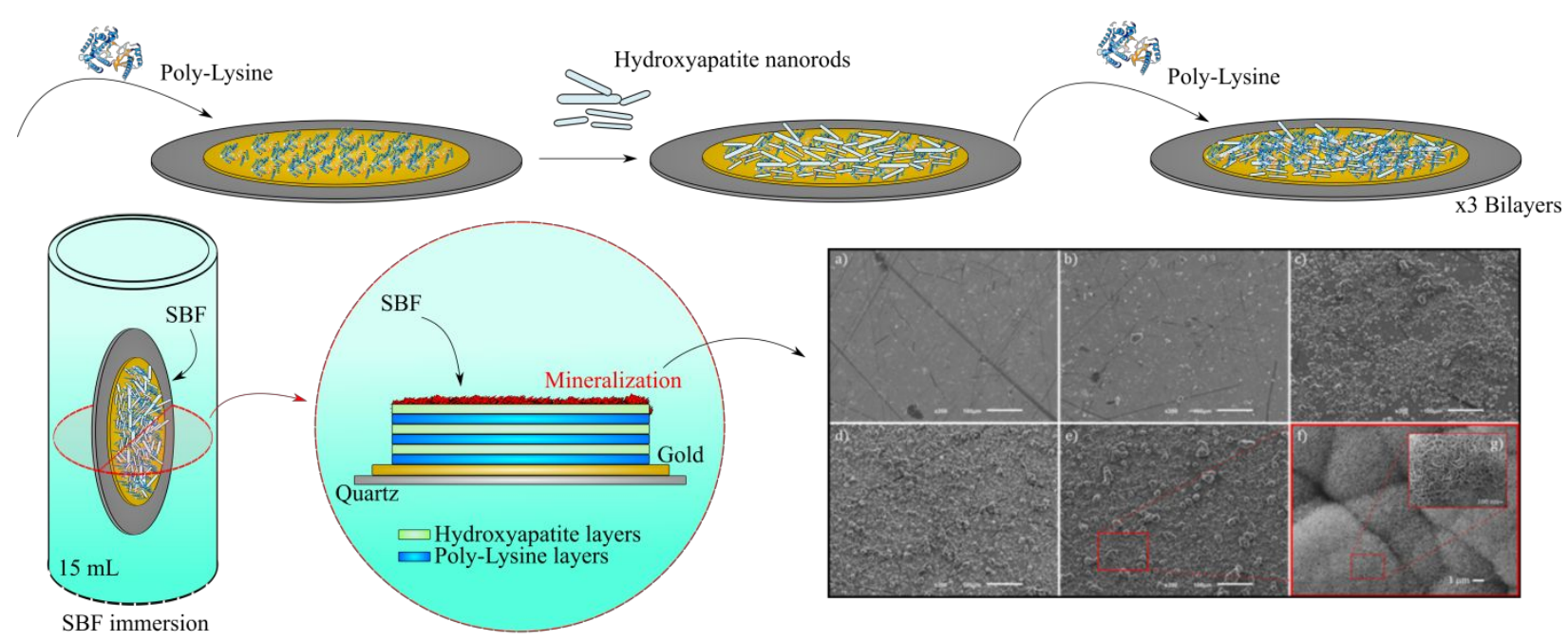

SYNOPSIS

In this work, we hypothesize that HAp nanoparticles can be immobilized into biomacromolecular ultrathin films to promote osteoconduction and enhanced osteoblasts response. We synthesized rod-like shaped HAp nanoparticles (96 nm long and $9 \mathrm{~nm}$ wide) with a surface charge of $14 \mathrm{mV}$ using a double-reactor microfluidic system. The negatively charged nanorods were incorporated into layer-by-layer $(\mathrm{LbL})$ constructs by alternating deposition with the polycation poly-L-lysine (PLL) on bidimensional gold and glass substrates. The opposite charge of these building blocks allowed a steady film growth of three PLL/HAp layers with thickness of about $70 \mathrm{~nm}$. The formation of mineralized hydroxyapatite was induced by soaking $[\mathrm{PLL} / \mathrm{HAp}]_{3}$ films in simulated body fluid. X-ray diffraction, energy-dispersive X-ray spectroscopy,and scanning electron microscopy confirmed the formation of the typical cauliflower-likemorphology found in crystalline hydroxyapatite after 7 days and a $\mathrm{Ca} / \mathrm{P}$ ratio of 1.91. SaOs-2osteoblast-like cells attached to the mineralized surfaces and developed long filopodia withlateral protrusions that promoted high spreading and adhesion strength, contrary to non-mineralized samples. We showcased that this class of LbL is osteoconductive and supports cell adhesion, spreading and viability, opening a wide range of possibilities to generate biocompatible interfaces for orthopedic implants and fixation devices. 




ACS Paragon PluRoodnlike mixed micelles

(High degree of ionization) 

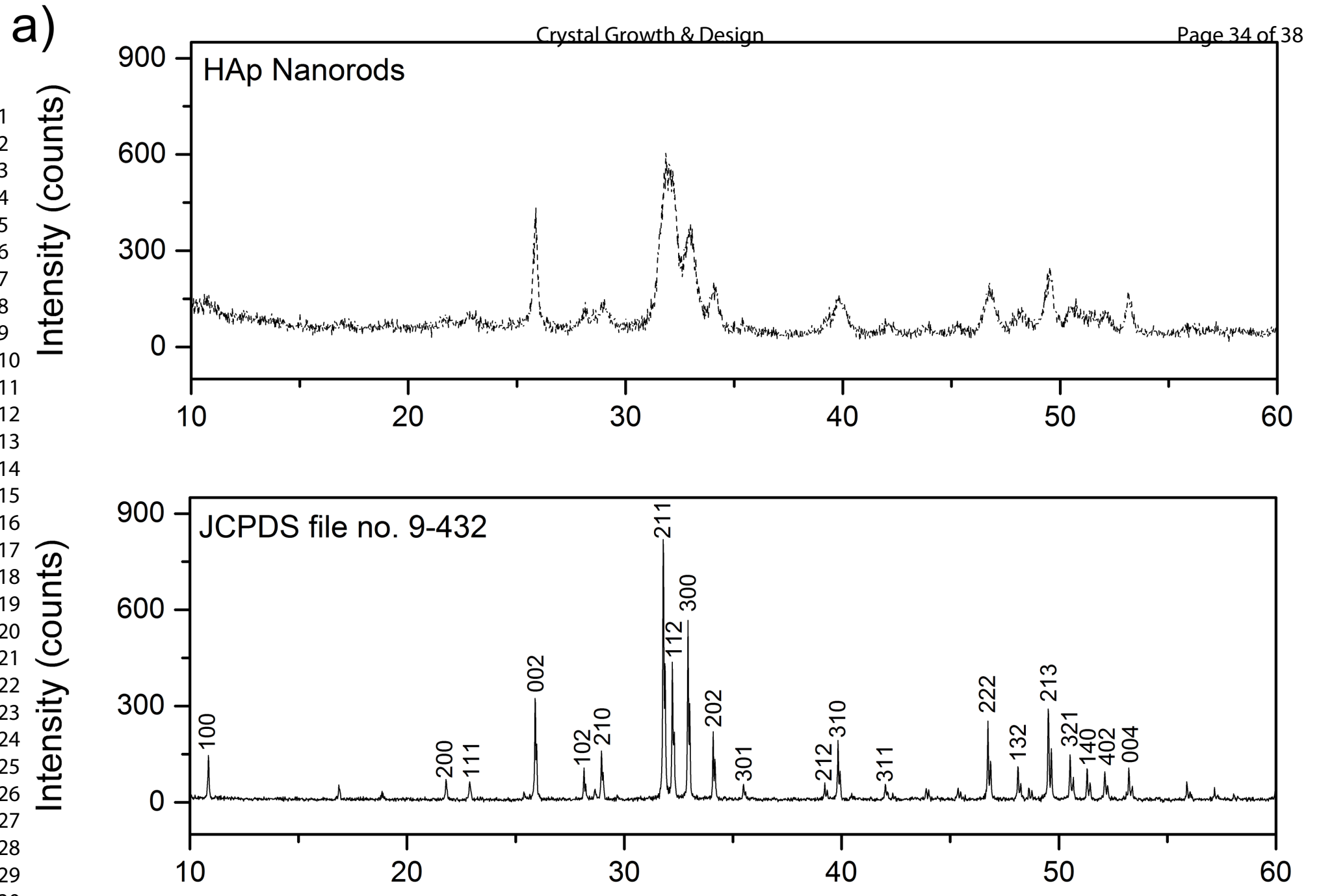

Difraction Angle, $2 \theta$ (deg.)
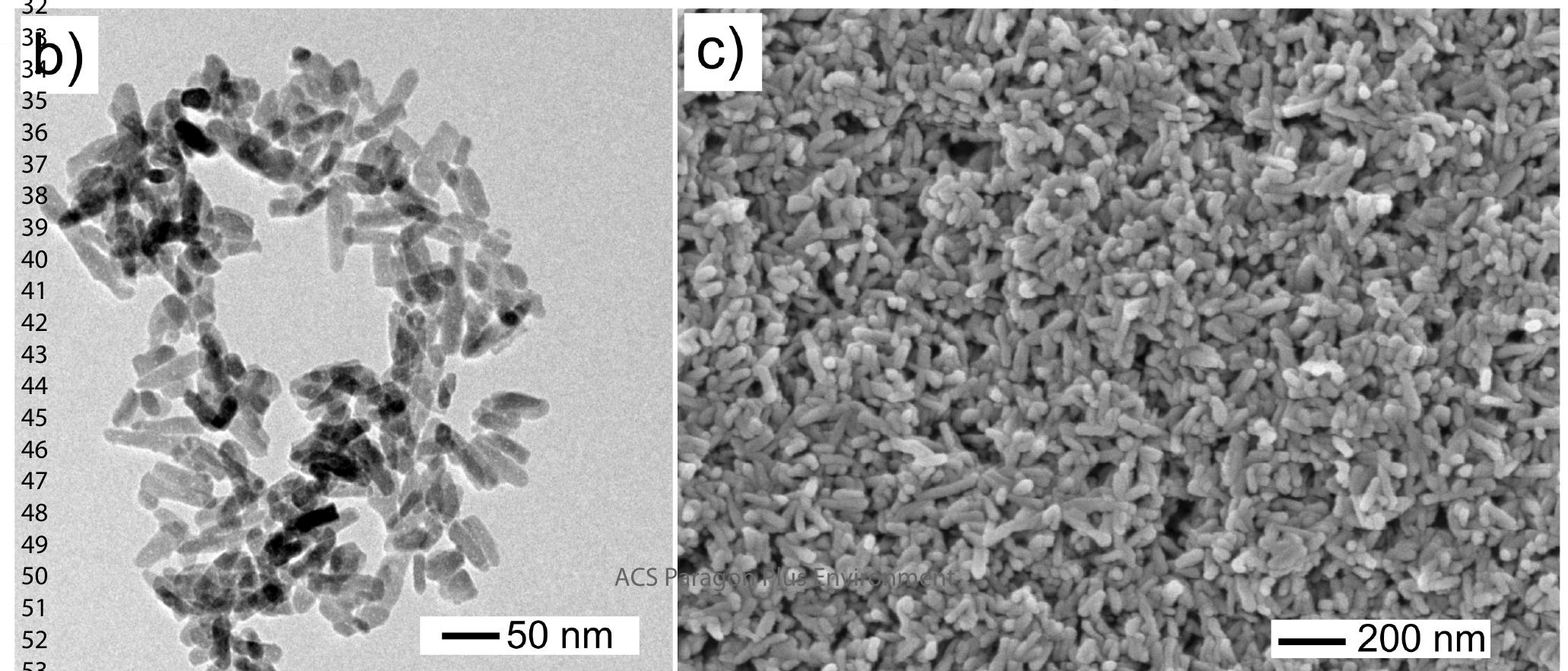
Pagaßj of $38 \quad$ Crystal Growth \& DesibD)

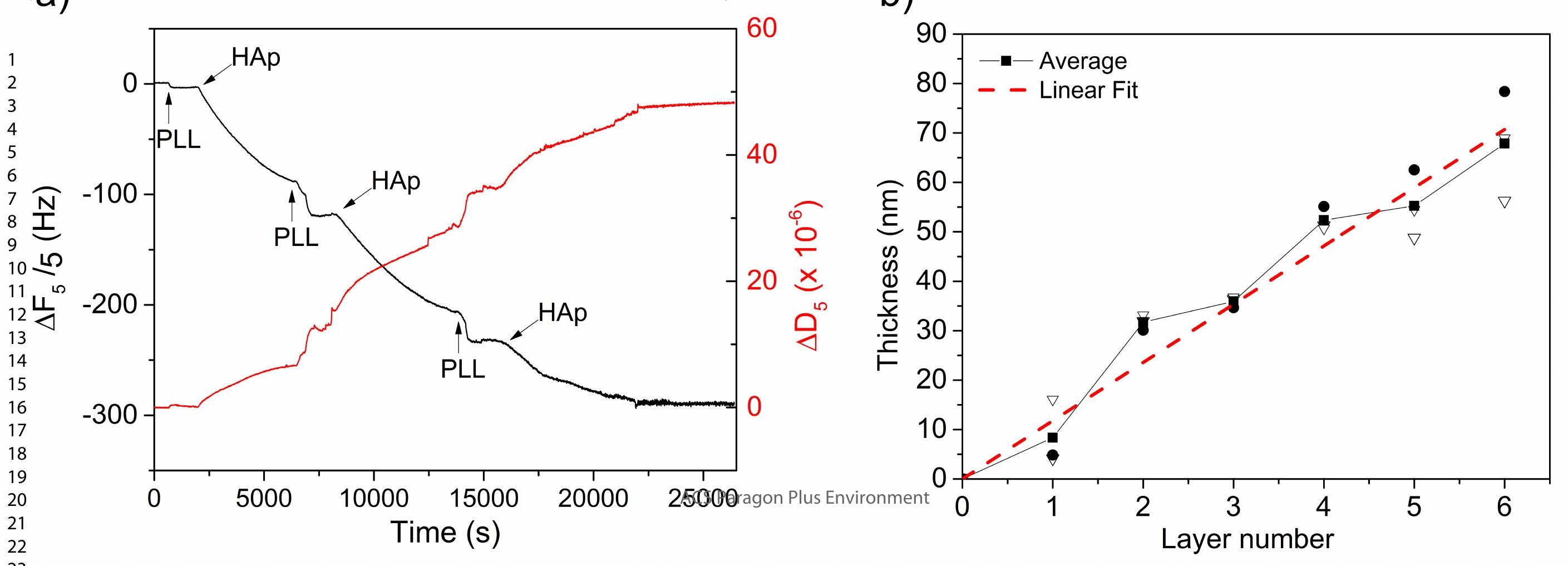


a)

Crystal Growth \& Design

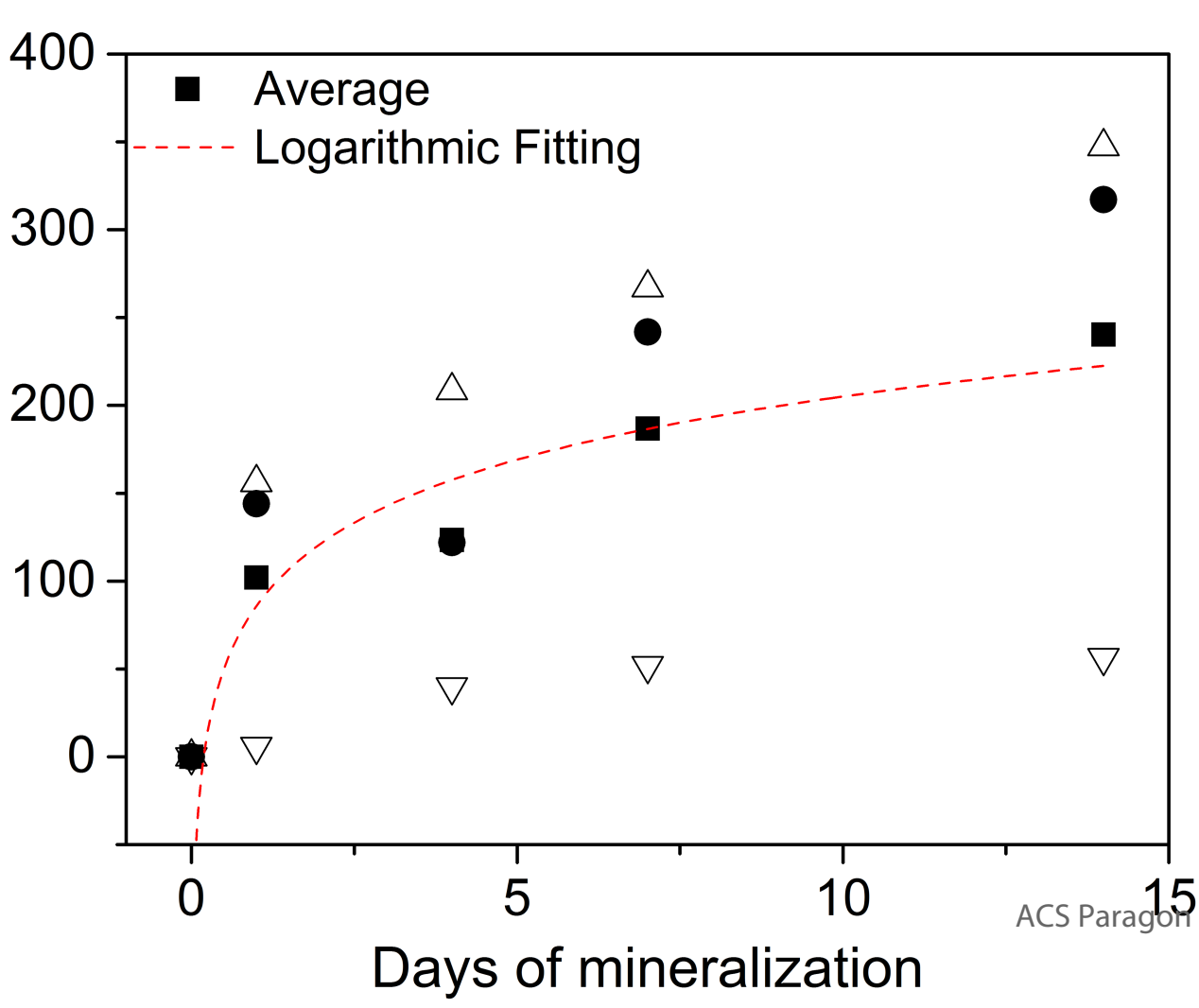

5 Plus Environment



Diffraction Angle, $2 \theta$ 
